\title{
Left mainstem bronchial laceration with perforation to right pleural cavity as complication after dynamic stent insertion
}

\author{
Mariusz P. Łochowski, Aleksandra Szlachcińska, Józef Kozak \\ Department of Thoracic Surgery, Medical University of Lodz, Poland
}

Videosurgery Miniinv 2014; 9 (2): 286-288

DOI: $10.5114 /$ wiitm.2014.41627

\begin{abstract}
The development of science at the end of the $20^{\text {th }}$ century introduced new surgical miniinvasive techniques. Endoscopic insertion of an internal stent is an alternative to other, older techniques in the treatment of tracheobronchial stenosis. Complications are serious and require immediate intervention. We report a case of a 53-year-old patient with left mainstem bronchus perforation during insertion of a dynamic stent. The clinical presentation was characterised by right tension pneumothorax. The dynamic stent in the right pleural cavity on computed tomography scan was observed. Right postero-lateral thoracotomy, stent evacuation and tracheal sutures were performed. Tracheal granulation was treated with argon plasma coagulation. Early diagnosis and treatment offered good current effects.
\end{abstract}

Key words: bronchial stent, bronchial injury, surgery.

\section{Introduction}

The development of science at the end of the $20^{\text {th }}$ century introduced new surgical miniinvasive techniques [1]. The insertion of an internal stent is a valuable method for the treatment of tracheobronchial stenosis. It is an alternative to other, older techniques. Serious complications after stenting have been described [2-4].

We report a patient with a left bronchial laceration after an attempt of dynamic stent insertion.

\section{Case report}

A 53-year-old man with tracheostomy after laryngeal resection due to carcinoma was treated in the pulmonology department due to tracheal benign stenosis for 3 years. Electrocoagulation of granulation tissue was performed many times. A plastic stent (Polyflex) was caught out. In June 2004 in the pulmonology department using rigid bronchoscopy insertion of a rigid dynamic stent was attempted (Photo 1). Cough and blood spitting occurred after insertion. Dyspnoea and subcutaneous emphysema appeared at the end of the endoscopic procedure. Tachypnoea and cyanosis and right thoracic pain suggested tension pneumothorax. A thoracic drain was inserted into the right pleural cavity. Air leak in the drainage was observed. A computed tomography (CT) scan showed right pneumothorax and the stent in the right pleural cavity (Photo 2). The patient was admitted to the department of thoracic surgery immediately. Laceration $(3 \mathrm{~cm}$ in length) of the membranous left mainstem bronchus was found in flexible bronchoscopy. The patient underwent a right postero-lateral thoracotomy through the fifth intercostal space. The stent was found in the pleural cavity. The laceration was sewn up with single 3-0 PDS sutures. Two drains were inserted into the pleural cavity. The patient was extubated early after the operation. Air leak was not 


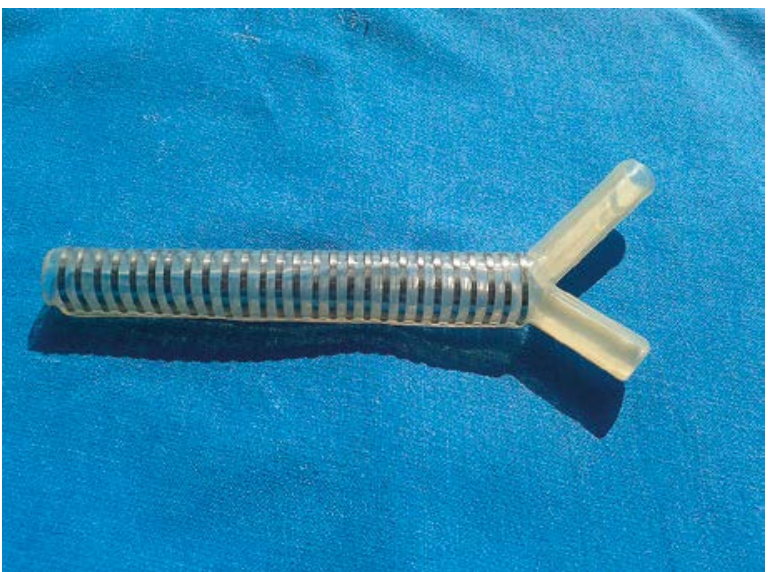

Photo 1. Rigid dynamic stent

observed. After 7 days flexible bronchoscopy was performed. Tracheal granulation was removed by using argon plasma coagulation in several sessions. In 7-year follow-up the patient did not require any surgical intervention.

\section{Discussion}

Acute lesions of the tracheobronchial tree are very rare and tend to be caused by iatrogenic injures rather than external trauma. These injuries are frequently caused by intubation, tracheotomies and bronchoscopies [5]. The frequency of tracheobronchial rupture after double-lumen tube intubations is estimated at $0.025-0.37 \%$ [6].

For many years chronic lesions of the trachea with stenosis after long-term intubation were treated surgically or by endoscopic dilatations, laser or argon plasma coagulation. Fast development of technology introduced various types of stents (self-expending, dynamic) for the treatment of this chronic disease. This method is not free from complications. Malposition or migration of the stent is common. Wallace and associates demonstrated a high incidence of migration $(87 \%)$ of wire stents [7, 8]. It is usually treated by insertion of a second or even third stent. Tracheobronchial wall perforation and erosion into the mediastinum, oesophagus or great vessels are reported as sequelae of the stent placement, and are often mortal [2-4]. In our department we use only self-expanding stents. The most common complications were migration and granulation in the end of the stent. We never had airway laceration. In our opinion indications for stenting of the airway first of all are

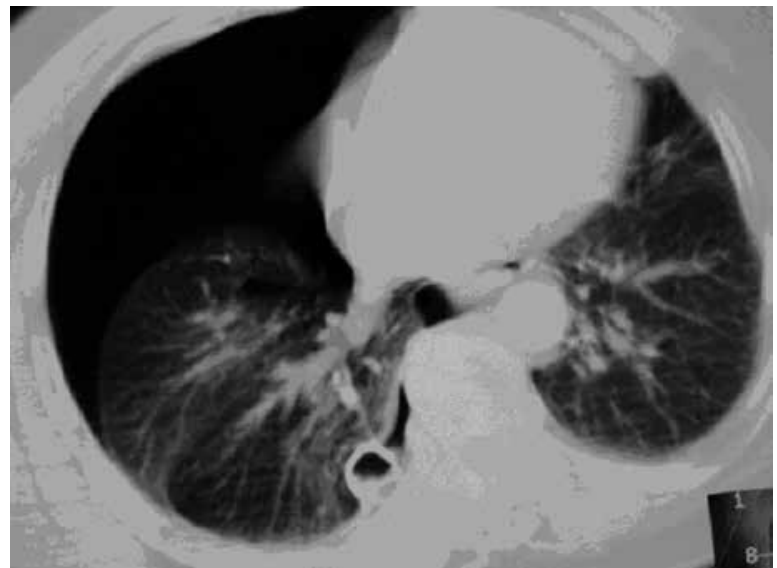

Photo 2. Dynamic tracheal stent in right pleural cavity. Right side pneumothorax

malignant stenosis. In the benign type we prefer laser and argon coagulation.

Clinical symptoms (mediastinal and/or subcutaneous emphysema, haemorrhage) appear often early after injury. The symptom of pneumothorax varies widely (from 0 to $60 \%$ ). Pneumothorax occurs only if the place of trauma communicates with the pleural space [5]. In our case all symptoms were present.

Fibreoptic bronchoscopy and conventional chest $\mathrm{X}$-ray are preferable tools in diagnosis. Bronchoscopy can successfully qualify the location, extent, and depth of the laceration and allows one to plan the optimal treatment. The role of CT in diagnosis of tracheobronchial rupture is controversial. The CT is sometimes necessary in some cases of non-detectable mediastinal bleeding or if penetration of mediastinal structures is suspected [5]. In our case right pneumothorax was observed but left mainstem bronchial membranous laceration was diagnosed by bronchoscopy.

The indications for surgery are based on clinical investigation, radiological and bronchoscopic findings [9]. Small tears (about $1 \mathrm{~cm}$ length), in the absence of gross air leak and minimal mediastinal and/or subcutaneous emphysema, can be treated conservatively, with continuous airway humidification, broad-spectrum antibiotics, and chest physiotherapy $[5,6,9,10]$. Lesions longer than $2 \mathrm{~cm}$, with the presence of extensive subcutaneous and/ or mediastinal emphysema and pneumothorax, are indications for early surgical repair $[5,9,10]$. In our case stent displacement to the pleural cavity, tension pneumothorax and $3 \mathrm{~cm}$ long tear were also indications for surgery. 
The surgical approach is determined by the location of the tear. Cervicotomy is preferable for cervical and upper thoracic tracheal injuries. The right thoracotomy in the fourth intercostal space is suitable for the $1 / 3$ lower thoracic part and bronchial injures $[5,9]$. In our case, although left mainstem bronchial membranous laceration was observed, right thoracotomy was performed due to the presence of the stent in the right pleural cavity.

To avoid any complications caused by the tube or elevated pressure of the artificial ventilation, early extubation with the patient's spontaneous respiration must be the aim in all patients [5].

\section{Conclusions}

In our opinion only early diagnosis allowed us to avoid mortal complications.

\section{References}

1. Bohanes T, Szkorupa M, Klein J, et al. Videothoracoscopic identification of chondromatous hamartoma of the lung. Videosurgery Miniinv 2013; 8: 152-7.

2. Conacher ID. Anaesthesia and tracheobronchial stenting for central airway obstruction in adults. $\mathrm{Br}$ J Anaesth 2003; 90: 367-74.

3. Nouraei SM, Pillay T, Hilton $\mathrm{CH}$. Emergency management of aorto-bronchial fistula after implantation of a self-expending bronchial stent. Eur J Cardiothorac Surg 2001; 20: 642-4.

4. Niwa H, Masaoka A, Yamakawa Y, et al. Esophageal tracheobronchoplasty for membranous laceration caused by insercion of a dumon stent - maintenance of oxygenation by percutaneous cardiopulmonary support. Eur J Cardiothorac Surg 1995; 9: 213-5.

5. Hofmann HS, Rettig G, Radke J, et al. Iatrogenic ruptures of the tracheobronchial tree. Eur J Cardiothorac Surg 2002; 21: 649-52.

6. Jougon J, Ballester M, Choukroun E, et al. Conservative treatment for postintubation tracheobronchial rupture. Ann Thor Surg 2000; 69: 216-20.

7. Hramiec JE, Haasler GB. Tracheal wire stent complications in malacia: implications of position and design. Ann Thorac Surg 1997; 63: 209-12.

8. Tchervenikov A, Tchalakov P, Tchervenikov P. Traumatic and iatrogenic lesions of the trachea and bronchi. Eur J Cardiothorac Surg 2000; 19: 19-24.

9. Gabor S, Renner $\mathrm{H}$, Pinter $\mathrm{H}$, et al. Indications for surgery in tracheobronchial ruptures. Eur J Cardiothorac Surg 2001; 20: 399-404.

10. Kalaud H, Smolle-Juttner FM, Prause G, et al. Iatrogenic ruptures of the tracheobronchial tree. Chest 1997; 112: 774-8.

Received: 4.01.2013, accepted: 24.09.2013. 